\title{
PENERAPAN ALGORITMA UNIFORM COST SEARCH (UCS) UNTUK REKOMENDASI PEMBANGUNAN RUMAH
}

\author{
Rellisa Dewi Zita Asmara ${ }^{1}$, Ridwan Yusuf S.T., M.T.I ${ }^{2}$,Sita Muharni, S.Kom, M.T.I ${ }^{3}$ \\ ${ }^{1}$ Program Studi Sistem Informasi, STMIK Dharma Wacana Metro \\ ${ }^{2,3}$ Dosen Tetap Sistem Informasi, STMIK Dharma Wacana Metro \\ Jalan Kenanga No.3 Mulyojati Kota Metro \\ Email :rellisadewizitaasmara@gmail.com
}

\begin{abstract}
ABSTRAK
Rumah merupakan bangunan untuk tempat tinggal, rumah merupakan tempat yang paling nyaman dan aman bagi setiap orang. Sehinggga dapat dikatan rumah adalah tempat berkumpulnya keluarga setelah seharian melakukan kegiatan diluar. Pengumpulan atau pemilihan tipe rumah pada CV.Wirawan Konsultan Bandar Lampung yang masih dilakukan secara manual menyebabkan kurang cepatnya informasi yang diperoleh oleh konsumen.Proses pengumpulan data tersebut dapat diperbaiki dengan penggunaan sistem penerapan algoritma uniform cost search(ucs) berbasis web yang terhubung ke database untuk data dan informasi tentang pemilihan tipe rumah, bentuk rumah dan transaksi yang tentunya lebih terstruktur dan lebih mudah.Selain itu, pengumpulan data dan penyebaran informasi dapat berjalan secara efisien. sistem penerapan algoritma uniform cost search(ucs)dirancang untuk menjadi media untuk berbagi informasi yang dapat bermanfaat bagi para pengguna sistem di masa mendatang. Perancangan sistem ini dibuat melalui berbagai tahapan yang dimulai dengan tahap perancangan sistem perangkat lunak menggunakan metode Object Oriented Software Engineering (OOSE), tahap perancangan antarmuka hingga tahap implementasi menggunakan bahasa pemograman $P H P$ dan databaseMySQL.
\end{abstract}

Kata kunci : PemilihanRumah,Uniform Cost Search (UCS)

\section{PENDAHULUAN}

\section{Latar Belakang Masalah}

Rumah merupakan bangunan untuk tempa ttinggal (KBBI, 2019). Namun sejatinya bagi beberapa orang rumah bukan hanya merupakan tempat tinggal, namun memiliki makna yang lebih dalam.Misalnya bagi beberapa orang rumah merupakan tempat berpulang, menciptakan ketenangan, ataupun menciptakan kebahagian dalam hati.Oleh karna itu rumah merupakan tempat yang paling nyaman dan aman bagi setiap orang.Nyaman dan aman bukan berarti rumah yang mewah, namun maksudnya memiliki arti yang besar bagi orang tersebut.Untuk mendapatkan rumah yang sesuai dengan kriteria di atas, maka sepertinya akan lebih cocok jika kita membuat rumah sendiri. Maksud dari membuat rumah sendiri bukan berarti kita yang benar benar membangun, tetapi maksudnya kita yang menentukan bentuk rumah kita seperti apa. Dalam proses pembuatan tersebut, akan dilewati fase pembangunan fisik rumah yang di dalamnya terdiri dari pembuatan dan penggabungan berbagai komponen rumah, seperti fondasi, tembok, jendela, pintu, dan masih banyak lagi.

Menurut Tamin, (2000) metode Uniform Cost Search (UCS) pernah digunakan untuk rute optimal berdasarkan kepadatan jalan pada waktu tertentu dapat mempengaruhi cepat atau lambatnya waktu tempuh yang dibutuhkan selama diperjalanan. Metode Uniform Cost Search (UCS) merupakan algoritmaSeach Tree (graph) yang digunakan untuk menyelesaikan beberapa persoalan . Algoritma ini memulai pencarian dari root node, kemudian dilanjutkan kenode-node selanjutnya. Dimana node tersebut dipilih yang memilki harga (cost) terkecil 


\section{Rumusan Masalah}

Berdasarkan latar belakang tersebut maka penulis membuat rumusan masalah yaitu bagaimana menerapkan metode Uniform Cost Search (UCS) kedalam sebuah sistem untuk rekomendasi pembangunan rumah.

\section{Batasan Masalah}

Dari masalah yang terlah diuraikan, agar permasalahan tidak terlalu luas dan terarah maka masalah yang ada perlu dibatasi, batasan masalah meliputi;

1. Algoritma yang digunakan adalah Uniform Cost Search (UCS).

2. Sistem ini dibangun berbasis website dengan menggunakan PHP dan MySQL.

3. Tidak membahas perbandingan Uniform Cost Search (UCS) dengan algoritma yang lainnya.

4. Kriteria inputan berupa budget konsumen, lokasi yang diinginkan, dan ukuran atau tipe rumah.

5. Output yang dihasilkan adalah rekomendasi pembangunan rumah

\section{LANDASAN TEORI}

\section{Search}

Menurut Luger (2005), search adalah sebuah teknik menyelesaikan masalah (problem solving) yang mengembangkan sebuah ruang permasalahan secara sistematik dalam sebuah proses. Terdapat 4 kriteria untuk menentukan performa sebuah metode pencarian, yaitu Completeness, Time Complexity, Space Complexity, dan Optimality.Metode pencarian dibagi menjadi dua strategi, yaitu uninformed search dan informed search. Uninformed search merupakan suatu strategi pencarian tanpa ada informasi mengenai cost (bobot) atau informasi tertentu sedangkan Informed search merupakan suatu strategi pencarian yang membutuhkan informasi mengenaicost (bobot) atau informasi tertentu.

\section{Uninformed Search}

Uninformed Search juga sering disebut dengan istilah Blind Search. Istilah tersebut menggambarkan bahwa teknik pencarian ini tidak memiliki informasi tambahan mengenai kondisi diluar dari yang disediakan oleh definisi masalah. Yang dilakukan oleh algoritma ini adalah melakukan generate dari successor dan membedakan goal state dari non-goal state. Pencarian dilakukan berdasarkan pada urutan mana saja node yang hendak di-expand. Jika solusi sudah ketemu, maka pencarian akan dihentikan

\section{Uniform Cost Search}

Uniform Cost Search adalah algoritma Seach Tree (graph) yang digunakan untuk menyelesaikan beberapa persoalan. Algoritma ini memulai pencarian dari root node, kemudian dilanjutkan ke node-node selanjutnya. Dimana node tersebut dipilih yang memilki harga (cost) terkecil dari root node. Algoritma ini merupakan modifikasi dari Bread First Search (BFS).

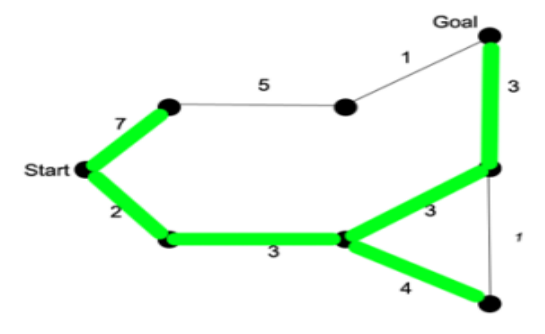

Gambar 1.Uniform Cost Search

\section{PHP (HyperText Preprocessor)}

Menurut Hikmah, dkk (2015:1) "PHP merupakan kepanjangan dari HyperText Preprocessor. PHP tergolong sebagai perangkat lunak open source yang diatur dalam aturan general purposelicences (GPL).Bahasa pemograman PHP sangat cocok dikembangkan dalam lingkungan web.Karena PHP dikhususkan untuk pengembangan web dinamis. Jadi dapat disimpulkan bahwa PHP adalah penerjemahan baris kode yang bisa dibaca atau dimengerti oleh komputer karena PHP bisa diletakan pada script HTML atau sebaliknya.

Kadir, Abdul (2018:2), Hypertext Preprocessor (PHP) merupakan Bahasa berbentuk skrip yang ditempatkan dalam 
server dan diproses diserver. Hasilnya yang akan dikirim ke klien, tempat pemakai menggunakan browser. PHP juga merupakan bahasa pemrograman yang bekerja dalam sebuah webserver, dimana script PHP dibuat harus tersimpan dalam sebuah server dan dieksekusi atau diproses dalam server tersebut.

\section{World Wide Web}

World Wide Web (WWW), yang lebih dikenal dengan istilah web, merupakan salah satu layanan yang didapat oleh pemakai komputer yang terhubung dengan internet. Dengan menggunakan teknologi hypertext, pemakai web dituntun untuk menemukan informasi dengan mengikuti link-link yang disediakan dalam dokumen web yang ditampilkan dalam browser web.

\section{UML (Unified Modelling Language}

Pada metode penelitian ini dilakukan rekayasa perangkat lunak yang digunakan adalah model Unified Modelling Language (UML) hanya berfungsi untuk melakukan pemodelan. Jadi penggunaan UML tidak terbatas pada metodologi tertentu, meskipun pada kenyataannya UML paling banyak digunakan pada metodologi berorientasi objek (Rosa A.S dan M. Shalahudin, 2014:133). Unified Modeling Language (UML) adalah Bahasa standar untuk pemodelan perangkat lunak dan untuk model proses bisnis dan memiliki muncul sebagai standar umum untuk pemodelan berorientasi objek (Touseef, Anwer, Hussain, \& Nadeem, 2015). Berdasarkan beberapa pendapat yang dikemukakan diatas dapat ditarik kesimpulan bahwa "Unified Modeling Language (UML) adalah sebuah bahasa yang berdasarkan grafik atau gambar untuk menvisualisasikan, menspesifikasikan, membangun dan pendokumentasian dari sebuah sistem pengembangan perangkat lunak berbasis $\mathrm{OO}$ (Object Oriented)" seperti pada gambar berikut ini:

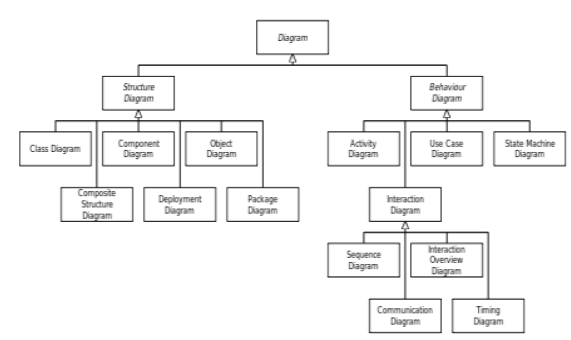

Gambar 1.Motode UML

\section{METODE PENELITIAN}

Metode penelitian yang akan digunakan dalam penelitian ini meliputi dua bagian yaitu metode pengumpulan data dan metode pengembangan sistem.

\section{A. Metode Pengumpulan Data}

1. Observasi

Penulis melaksanakan metode ini untuk mendapatkan data dengan pengamatan secara langsung keperusahaan $\mathrm{Cv}$ Wirawan Konsultan Bandar Lampung untuk melakukan penelitian, pemantauan, ataupun terlibat secara langsung dengan prosedur sistem yang berjalan pada saat ini.

Contohnya saja pada sistem penerapan algoritma Uniform Cost Search (UCS) dalam penerapan rekomendasi pembanguan rumah belum terlengkapinya data perumahan untuk setiap wilayah kususnya wilayah metro sehingga saat akan melakukan pengecekan data-data perumahan membutuhkan waktu yang lumayan lama.

\section{Wawancara}

Penulis melakukan wawancara kepada pemilik perumahan untuk memperkuat dan memperjelas temuan saat observasi yang merupakan pelaku sistem pada saatini, serta para pencari kerja di lapangan.

Wawancara ini dilakukan agar peneliti lebih paham terdapat data apa saja yang terdapat didalam proses pembangunan perumahan sehingga penulis dapat lebih mudah dalam pengembangannya.

3. Studi Pustaka

Penulis melakukan metode ini untuk memenuhi informasi penelitian, sehingga berusaha mendapatkan data dengan cara melihat, membaca, serta mencoba menafsirkan dan mengembangkan informasi yang berkaitan dengan masalah yangdibicarakan sebagai referensi serta 
penunjang penelitian dalam $m$ penyusunan laporan.

\section{B. Metode Pengembangan Sistem}

Dalam penelitian ini kerangka pengembangan perangkat lunak yang digunakan penulis adalah metode yang berbasis object oriented yaitu Object Oriented Software Engineering (OOSE). OOSE merupakan bahasa pemodelan object dan metodelogi yang dikembangkan oleh ivar jacobson pada tahun 1992. OOSE ialah suatu rekayasa perangkat lunak yang digunakan untuk membangun sebuah software dengan melalui serangkaian proses terlebih dahulu. OOSE ini merupakan salah satu model/konsep dalam perancangan suatu rekayasa piranti perangkat lunak sebelum melakukan pengkodean. Konsep ini mulai banyak digunakan tetapi konsep object oriented ini tidak dapat menjangkau formalitas yang dapat dicapai oleh bahasa formal. Konsep OOSE sendiri menggunakan metode Unified Modeling Language (UML). OOSE memiliki siklus diantaranya :

\section{Analysis Requiment (analisis kebutuhan)}

a. Perangkat keras (Hardware)

Laptop dengan spesifikasi intel core i3, processor 2,40 GHz, harddisk $320 \mathrm{~Gb}$, RAM $2.00 \mathrm{~GB}$, Flashdisk 16 gb sebagai media penyimpanan data.

b. Perangkat Lunak (Software)

Prangkat lunak yang digunakan sebagai alat bantu dalam penelitian ini adalah : Operating System Windows 7, Microsoft office 2007, Pemrograman PHP, Xampp, dreamweaver microsoft visio 2007, Mozila Firefox, Paint.

\section{c. Pengguna Sistem \\ 1. Admin}

Disini admin atau developer memiliki tugas untuk menginputkan informasi tentang kelengkapan yang dibutuhkan konsumen misalnya tentang harga atau budget, lokasi, tipe atau ukuran rumah sesuai yang diminati oleh konsumen.

\section{Konsumen}

Konsumen disini akan dapat melihat informasi yang sudah diberikan oleh admin atau developer tentang rekomendasi pembangunan rumah tanpa harus mendatangi tempat konsultan.

\section{Construction}

a. Design (Desain)

Pada tahap perancangan ini merupakan tahap lanjutan dari analisis kebutuhan dimana pada perancangan ini peneliti menggambarkan rancangan yang akan dibangun sebelum dikatakan pengkodean kedalam sebuah pemrograman. Dalam perancangan ini penulis menggunakan tool UML (Unifiel modelling language) sebagai rancangan dari sebuah model sistem yang akan dibangun, yang mencangkup perancangan use case, activity diagram,sequence diagram, class diagram dan perancangan interface.

\section{b. Implementation (Implementasi)}

Tahap implementasi merupakan tahap dimana pada tahapan ini peneliti mengimplementasikan rancangan dan menerapkan metode Uniform Cost Search (UCS) kedalam sistem yang dituangkan kesebuah aplikasi yang menggunakan bahasa pemograman PHP dan database Mysql.

c. Testing

Pada fase ini sistem diverifikasi untuk memastikan bahwa sistem dirancang sesuai dengan spesifikasinya. Testing dilakukan dengan menggunakan balckbox testing. Tetapi pada aplikasi penerapan algoritma uniform cost search (ucs) untuk rekomendasi pembangunan rumah tidak sampai pada tahap testing, hanya berahir pada tahap implementasi saja.

\section{HASIL DAN PEMBAHASAN}




\section{A. Usecase Diagram}

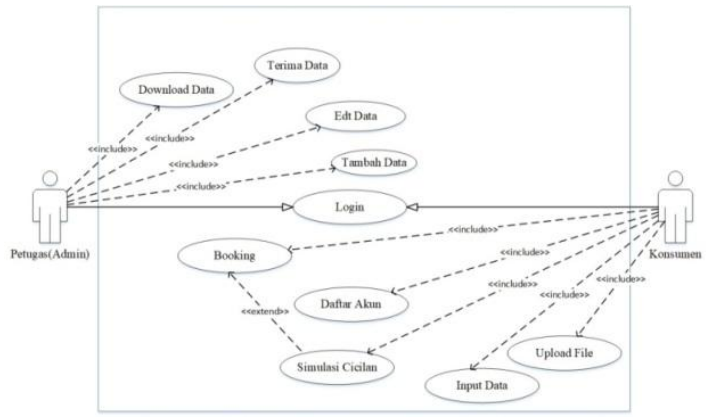

Gambar 2.Usecase Diagram

\section{B. Activity Diagram Sistem Yang Diusulkan}

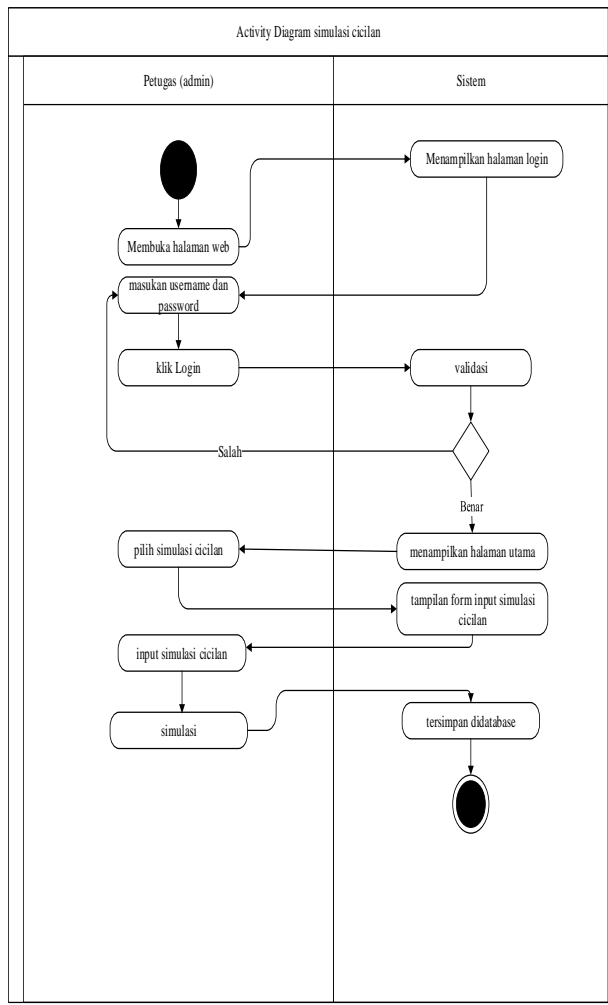

Gambar 3. Activity Diagram Sistem Yang Diusulkan

\section{Sequance Diagram Sistem Yang} Diusulkan

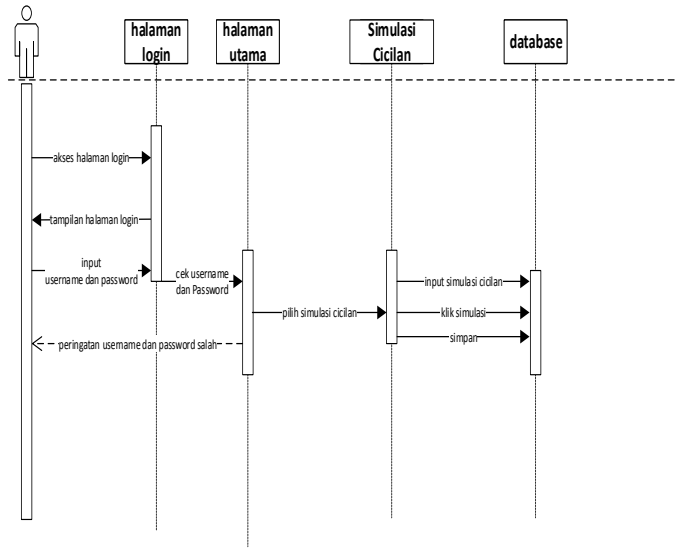

Gambar 4. Sequance Diagram Sistem Yang Diusulka

\section{Class Diagram}

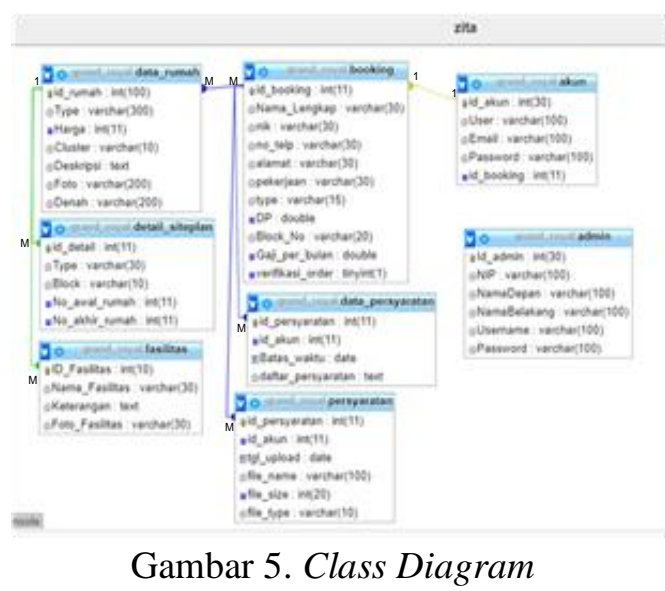

E. Implementasi

1) Tampilan menu Login

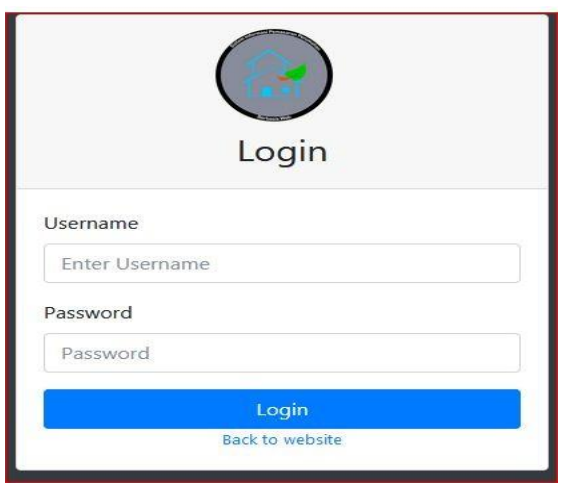

Gambar 6. Menu Login

2) Tampilan menu Register

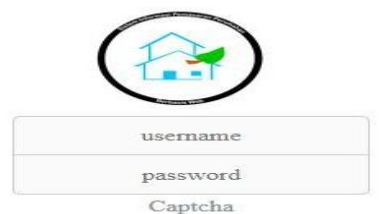

\section{1}

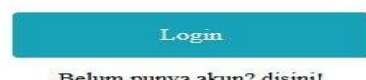

Belum punya akun? disini

Gambar 7. Tampilan menu Register

3) Tampilan halaman utama 


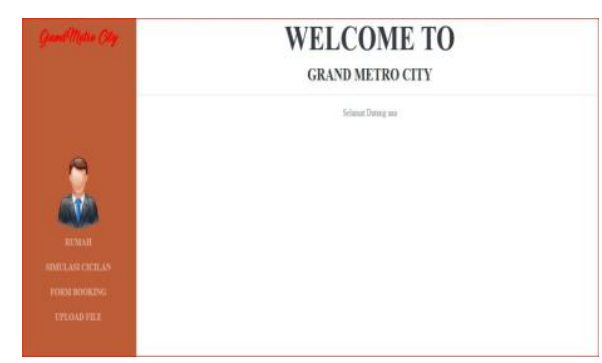

Gambar 8. Tampilan menu utama

4. Tampilan Tambah Data Perum

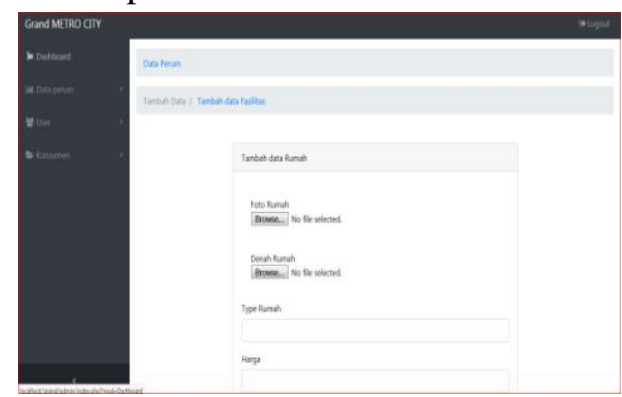

Gambar 9. Tampilan Tambah Data Perum

5. Tampilan Edit Perum

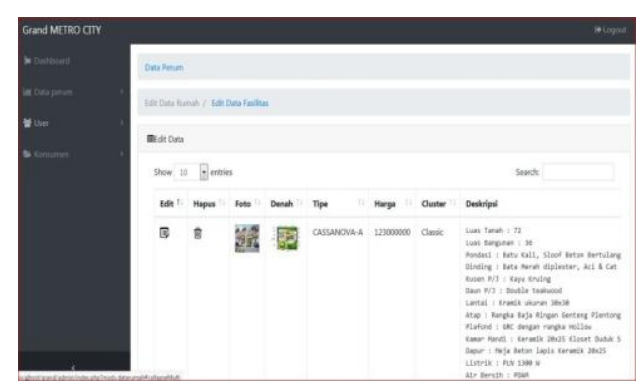

Gambar 10. Tampilan Edit Perum

5. Tampilan tambah User

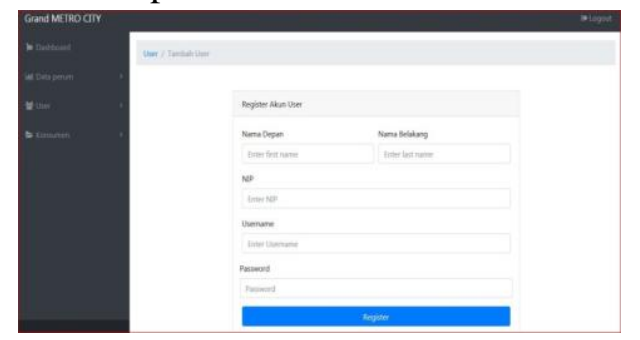

Gambar 11. Tampilan tambah User

6. Tampilan Edit User

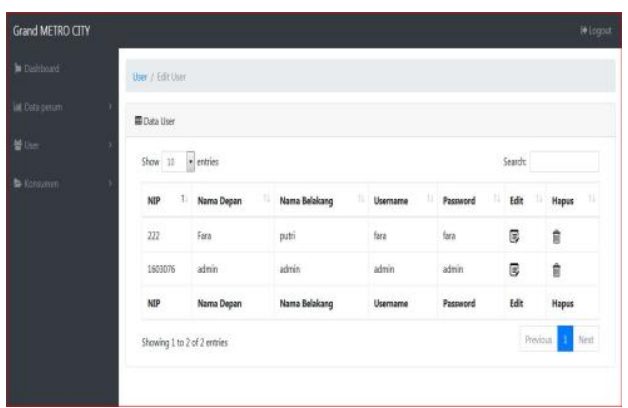

Gambar 12. Tampilan Edit User

7. Tampilan data Konsumen

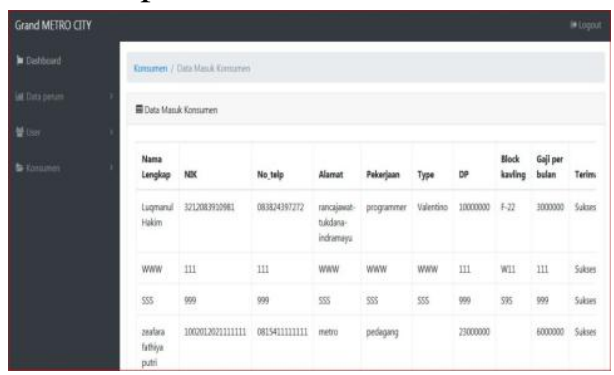

Gambar 13. Tampilandata Konsumen

8. Tampilan form Verifikasi

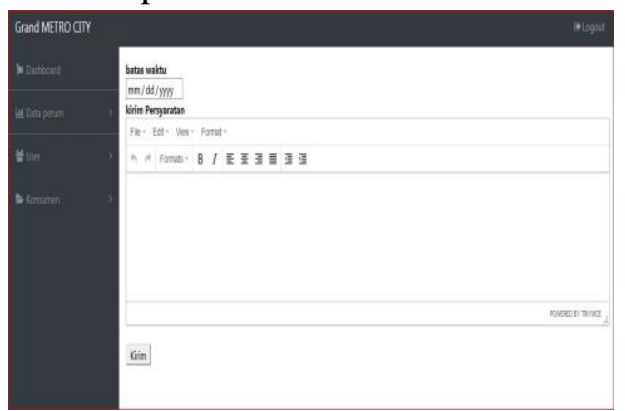

Gambar 14. Tampilan form Verifikasi

9. Tampilan Data Persyaratan Konsumen

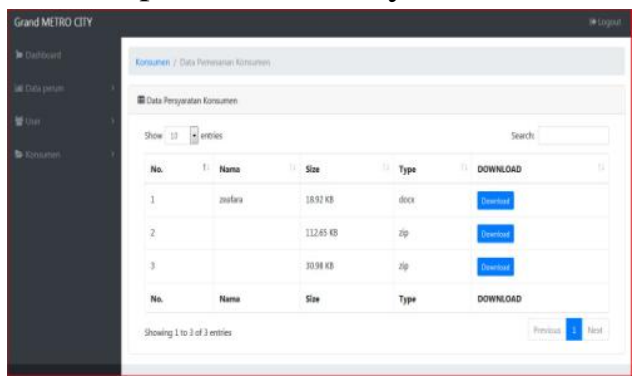

Gambar 15. Tampilan Data Persyaratan Konsumen

10. Tampilan Menu Data Finansial 


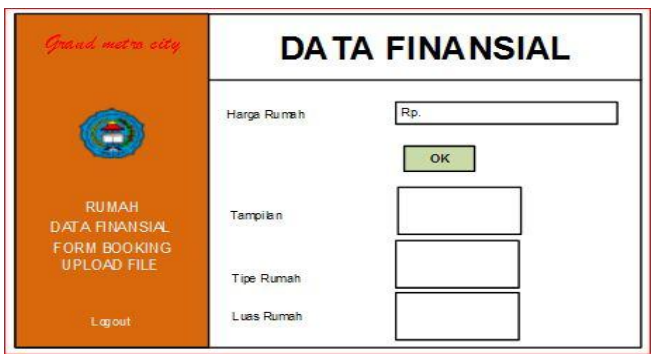

Gambar 16. Tampilan Menu Data Finansial

11. Tampilan Menu Form Booking

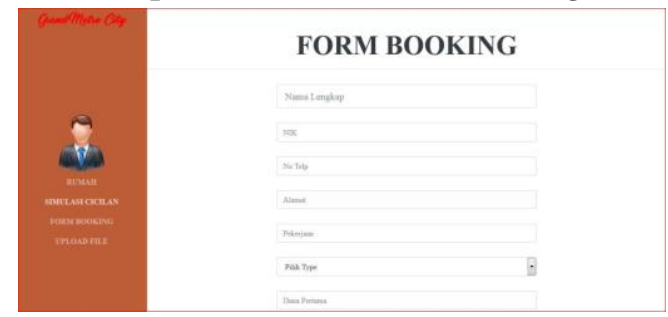

Gambar17Tampilan Menu Form Booking

12. Tampilan Menu Upload File

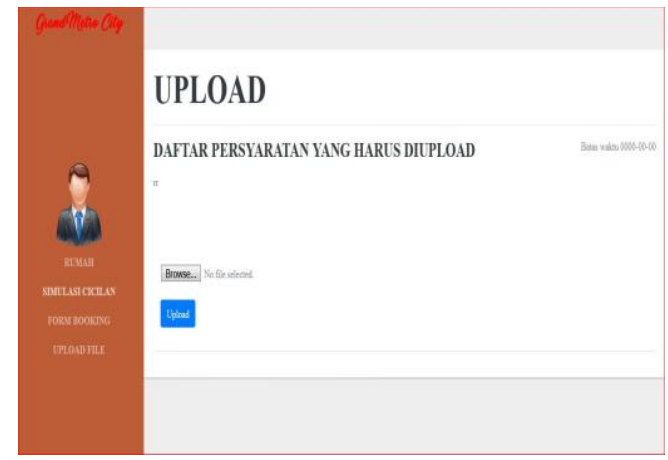

Gambar 18. Tampilan Menu Upload File

\section{KESIMPULAN DAN SARAN}

\section{A. Kesimpulan}

1. Dari hasil analisis ada beberapa permasalahan yang sering terjadi dalam pencarian rumah, konsumen yang ingin mencari rumah harus mendatangi CV.Wirawan Konsultan Bandar Lampung dan bertanya kepada admin tentang informasi perumahan yang akan dicari, sering kali terkadang tidak cocok dalam bentuk, tipe maupun harga hal ini membuat waktu para konsumen terbuang dalam pencarian rumah.

2. Pada sistem "penerpan algoritma Uniform Cost Search (UCS) untuk melakukan rekomendasi pembangunan rumah" dimana pada sistem ini terdapat perhitungan algoritma yang terletak pada data finalsial. Pada data finansial apabila user memasukkan nominal, maka secara otomatis bentuk rumah, tipe rumah, luas tanah akan muncul sesuai dengan nominal yang dimasukkan oleh user.

3. Dari sistem yang sudah ada dan yang diusulkan dapat ditarik kesimpulan bahwa pada sistem yang diusulkan mampu memberikan kemudahan bagi user dalam pemilihan rumah, sehingga user dapat melakukan transaksi, dan mencari informasi tipe rumah tanpa harus datang ke CV.Wirawan Konsultan Bandar Lampung.

\section{B. Saran}

1. Melakukan backup data dan update data secara berkala agar apabila terjadi kerusakan pada sistem, data-data yang ada tidak hilang.

2. Mengingat pembuatan penerpan algoritma Uniform Cost Search (UCS) untuk melakukan rekomendasi pembangunan rumah masih memiliki banyak kelemahan didalamnya, seperti belum adanya letak goegrafis, sehingga pada sistem penerpan algoritma Uniform Cost Search (UCS) untuk melakukan rekomendasi pembangunan rumah ini belum bisa menampilkan letak rumah yang berada pada pegunungan, bukit, dan disekitar pantai.

\section{DAFTAR PUSTAKA}

1. Sutanto, Joko. 2006. PrediksiAwal Pembangunan Proyek Perumahan. Bandung: PT. Citra Pindo bandung.

2. Daihani, Dadan Umar. 2001. Komputerisasi Pengambilan Keputusan Berbasis Komputer. Jakarta: PT Elex Media Komputindo. 
3. Jogiyanto HM. 2001 Analisis dan

Disain Sistem Informasi. Yogyakarta :Andi

Yogyakarta..

4. E. Widiastuti and S. Handayani,

2013. AnalisisFaktor-Faktor yang

Mempengaruhi Keputusan Pembelian Rumah

Bersubsidi dengan Menggunakan Analisis

Regresi, in Prosiding Seminar Nasional

Statistika Universitas Diponegoro.Fakultas

Ekonomi, UniversitasDiponegoro. Semarang.

5. Renggo, 2006, Menghitung Biaya

Membuat Rumah, Swadaya, Jakarta.

6. Jurnal Ilmiah Penelitian dan

Penerapan Taknologi Sistem Informasi Vol.3

No.1 February 2019.

7. D.K Ching, F.

(2008).Arsitektur:Bentuk, RuangdanTatahan.

Jakarta :Erlangga.

8. Marlina, E, (2006). Perencanaan dan

Pengembangan Perumahan. Yogyakarta :

Andy Yogyakarta.

9. Sadyohutomo, (2008).Manajemen

Kota dan Wilayah.Jakarta :BumiAksara.

10. Yudohusodo, S. (1991).Rumah

Untuk Seluruh Rakyat. Jakarta :Inkoppol,

Unit Percetakan Bharakerta. 